\title{
A COMPETITIVIDADE DAS EMPRESAS COM O SCM
}

\author{
Israel Ribeiro Alves ${ }^{1}$
}

RESUMO: O presente artigo possui como objetivo verificar através de pesquisa bibliográfica, com o seguinte tema, como as empresas estão mais competitivas com a gestão na cadeia de suprimentos, e como o gerenciamento pode ser ferramenta de estratégia contribuindo para a competitividade vantajosa. O objetivo desse trabalho é demonstrar que a gestão nas cadeias de suprimentos, vem sendo um elemento importante para competitividade vantajosa, com visão relacional, associada a inserção da firma em redes de relacionamentos para o desenvolvimento de recursos relacionais, com base na diminuição dos custos nas operações logísticas gerando maior valor aos consumidores sendo que, o nível de competitividade aumentou entre as organizações, forçando várias empresas a reestruturar seus processos, tornando as flexíveis, com uma qualidade melhor e também com o menor custo para a permanência no mercado cada vez mais vem sendo competitivo. Com o gerenciamento nas cadeias e suas etapas para o aperfeiçoamento dos processos, desde dos fornecedores até os consumidores, gera solidez e valor nos elos na cadeia de suplementos, nos últimas anos as empresas perceberam o quanto a competitividade é importante e ao mesmo tempo vantajosa gerando valor positivo para os negócios, sendo que a gestão dessa área contribui para que as organizações obtenham o seu diferencial competitivo e maximizem valores, é através de práticas adotadas com a gestão na cadeia de suplementos acompanhando as evoluções para a competitividade sustentável.

Palavras-Chave: Competitividade Vantajosa. Gestão. Qualidade.

ABSTRACT: This article aims to verify through bibliographic research, with the following theme, how companies are more competitive with the supply chain, and how management can be a strategy tool, contributing to the advantageous alternative. The objective of this work is to demonstrate that the management of supply chains, has been an important element to avoid advantageous, with a relational view, associated with the insertion of the company in development networks for the development of relational resources, based on the reduction of costs in logistical operations generating greater value for consumers, the level of which has increased between associations, forcing several companies to restructure their processes, making them flexible, with better quality and also with the lowest cost for remaining in the market, which has become increasingly competitive. With the management of the chains and their steps for the improvement of

\footnotetext{
${ }^{1}$ Administrador e consultor com registro no CRA-SC 28764, graduado no curso de administração de empresas pela Faculdade De Ciências Administrativas E Contábeis, Centro Universitário Da Grandes Dourados, UNIGRAN. Pós-graduação em MBA executivo em administração com ênfase em recursos humanos, Centro Universitário da Grandes Dourados, UNIGRAN. Cursando mestrado em administração, pela Must University (Florida- USA).
} 


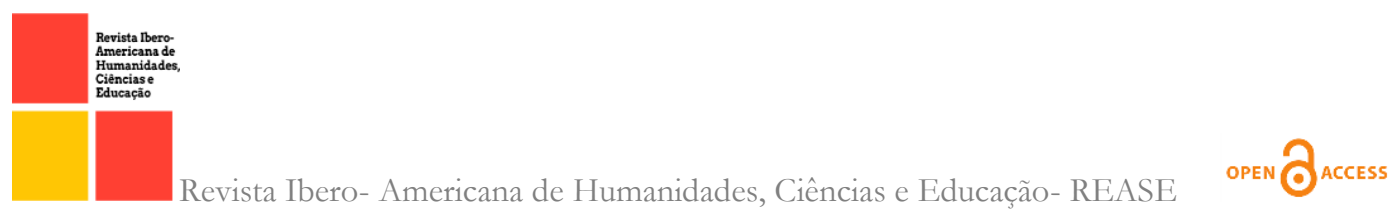

the processes, from the suppliers to the consumers, it generates solidity and value in the links of the supplements chain, in the last years as the companies perceive how important it is and at the same time advantageous generating positive value for the businesses, and the management of this area contributes to the associations obtaining their differential and maximizing values, it is through practices adopted with the management of the supply chain following the developments for sustainable defense.

Keywords: Advantageous Competitiveness. Management. Quality.

\section{INTRODUÇÃO /METODOLOGIA}

Este paper apresenta pesquisa investigativa através de websites, sobre o tema a competitividade das empresas no mercado com relação a cadeia de suprimentos, sendo que o consumidor está mais informado e ao memo tempo mais exigente em relação aos produtos e serviços, o qual procura estabelecer um relacionamento único com a empresa, com o conceito de que não é, o ter, mais importante, e sim, o usar. Com foco no crescimento em um ambiente competitivo, o SCM vem através das práticas de gestão na cadeia de suprimentos reduzir o tempo de ciclo e inventários, otimizando a logística e serviços mais eficiente, com as integrações das áreas organizacionais, com resultados comuns a todos os envolvidos no SCM, afim de seja percebida pelos clientes. Parece ser simples, porém, o Supply Chain, não é tão simples quanto parece, é necessário que haja o apoio dos envolvidos para haver sucesso, em especial dos gestores em garantir que suas equipes estejam comprometidas com os objetivos, e os mesmos cientes de que cada ação tomada impactará e refletirá no restante das ações, considerando que o Supply Chain tem encontrado barreira na implantação dentro de algumas empresas, pois muitas não conseguem fazer a integração das as áreas com comprometimento de manter o funcionamento na cadeia de suprimentos para o seu sucesso.

Em relação a redução dos custos, desperdícios, a gestão na cadeia de suprimentos oferece vantagens aumentando a eficiência produtiva, demonstrando que os fornecedores diretos não são o início na cadeia e os clientes não são o fim dela, transformando as empresas e clientes, em uma rede entre fornecedores de maneira que todos se comuniquem produzindo informações para que sejam elaboradas estratégias, 


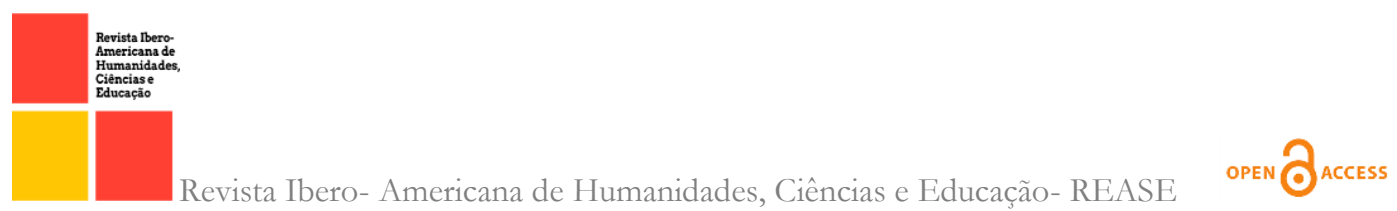

identificando os pontos para melhoria nos fluxos e nos processos, com diferenciação para obter vantagens competitivas frete aos concorrentes.

\section{DESENVOLVIMENTO - REVISÃO DE LITERATURA}

\section{CADEIA DE SUPRIMENTOS}

O conceito de SCM, inicialmente está relacionado com a perspectiva de integração dos processos, nos quais diferentes membros na cadeia de suplementos reúnem esforços para coordenar as atividades ou processos específicos o objetivando satisfazer todos os clientes, e evoluindo para uma visão mais sistêmica e estratégica, alocando recursos e esforços para implementar uma estratégia única na cadeia, melhorando para obtenção de vantagem competitiva, com custos reduzidos e satisfazendo melhor os clientes, e todos os participantes.

De acordo com (MIGUEL \& BRITO, 2009). O SCM é um conceito bastante abrangente que não se limita a uma área específica de conhecimento e considera que várias empresas adotam as práticas de gestão integrada, com consequente aumento na vantagem para competitividade, e redução de custos, com melhor satisfação do cliente.

O SCM se destaca em focalizar no consumidor com um destaque excepcional buscando equacionar a cadeia de suprimentos atendendo de forma desejada, e a integração do SCM nos processos industriais e comerciais vem sendo, partindo do consumidor final ao os fornecedores iniciais gerando produtos, serviços e informações que agregam valor apara os clientes.

\section{EVOLUÇÃO DA INTEGRAÇÃO NA CADEIA DE SUPRIMENTOS}

A gestão na cadeia de suprimentos, é uma extensão da lógica da logística, para isso a logística foca sua atenção a os fluxos dentro da organização, e a gestão na cadeia de suprimentos, na integração e na evolução da posição do estágio um da independência funcional, em que cada função de negócios, como a produção ou compra, faz seu próprio trabalho em completo isolamento de outras funções, reconhecendo que a empesa tem necessidade de um grau limitado de integração entre funções, como a distribuição e 


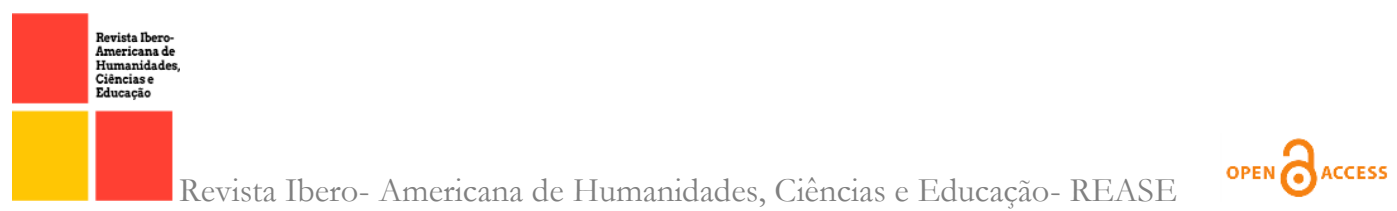

gerenciamento de estoques ou de compra, e controle de materiais. Conforme (Christopher, 2012). O desenvolvimento econômico sustentável, através da governança corporativa contribui para melhor desempenho das empresas, evitando assim diversos fracassos empresariais como abusos de poder.

\section{I Fonte da competitividade}

A fonte de vantagem competitiva está relacionada a dois pontos principais, o primeiro na capacidade da organização de se diferenciar de seus concorrentes aos olhos do cliente, e o segundo na capacidade em operar com custo menor.

Os princípios que fundamentam o gerenciamento do SCM, é o fluxo eficiente de materiais e de informação para atender às exigências dos clientes, e as organizações empresariais reconhecem o impacto vital que o gerenciamento logístico na cadeia de suprimentos para obtenção de vantagem e competitividade.

Conforme para (Novaes, 2015). Fazer a gestão da cadeia de suprimentos corresponde a integrar os processos industriais e comerciais, partindo do consumidor final e indo até os fornecedores iniciais, gerando produtos, serviços e informações que agreguem valor para os clientes.

A Logística Empresarial desenvolveu quatro tipos de valores positivos, como o valor de lugar em que o produto deve estar no lugar certo, o do tempo em que o produto deve estar disponível na hora certa, o de qualidade em que o atendimento as expectativas do cliente, e a de informação aonde se tem o acompanhamento em tempo real do status do pedido. De acordo com (NOVAES, Logística e gerenciamento da cadeia de distribuição, 2015). Além de agregar quatro tipos de valores positivos, a logística procura também eliminar do processo tudo que não tenha valor para o cliente, ou seja, tudo que acarrete apenas custos e perda de tempo

\subsection{Redução de custos e produtividade}

A cadeia de suplementos pode aumentar a eficiência com o gerenciamento e a logística da e a produtividade, contribuindo de maneira significativa para a redução dos 


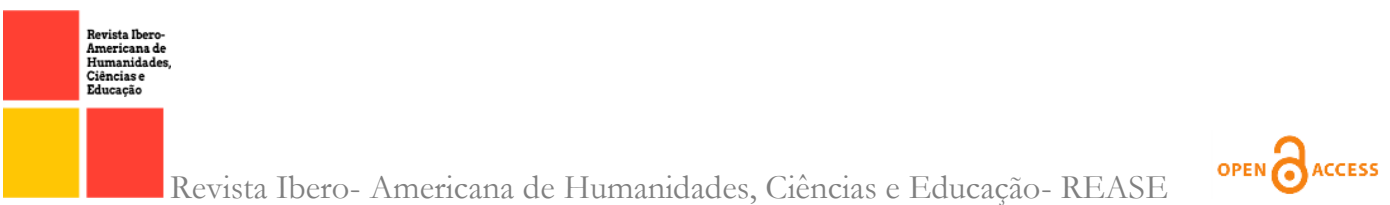

custos de produção, diminuindo o custo por unidade de produto, ofertando produtos ou serviços certos no lugar certo, no momento certo e nas condições desejadas, contribuindo para a empresa, e diferenciando as ofertas de produtos em relação aos da concorrência.

De acordo com (Miguel \& Brito, 2009). Define que na prática, diversas empresas passaram a adotar técnicas de gestão de suprimentos para melhorar seu desempenho, e com a adoção da gestão na cadeia de suplementos os custos da empresa foram afetados significativamente, e as tomadas decisões nos processos proporcionam níveis diferentes de serviços aos consumidores, de maneira eficaz em relação a outros mercados, aumentando seus os lucros. Portanto, uma boa gestão não gera somente vendas, e reduz custos.

\section{CARACTERÍSTICAS PARA VANTAGEM COMPETITIVA}

Existem fatores que influenciam para o alcance das características competitiva, como relacionamento entre fornecedores e os clientes, o sistema de produção, o grau tecnológico empregado, sendo que não há fórmula mágica, e sim a resposta está dentro de cada empresa.

Conforme (NOVAES, 2004). Afirma que uma cadeia de suprimentos é a integração dos processos industriais e comerciais, partindo do consumidor final seguindo até os fornecedores iniciais, gerando produtos e serviços com informações que agreguem valor para o cliente.

Para se atingir um grau de agilidade mais eficiente na cadeia, é uso de ferramentas de tecnologia de informação, com uma estratégia de alocação de estoques de forma intensiva, observando o padrão de consumo, caso haja mudanças, pode ser detectadas e então as estratégias entre fornecedores e clientes podem ser delineadas facilmente com as filiais ligadas online, e centros de distribuição tendo informações real-time do consumo e provedores logísticos cientes dos níveis de produtos, com estoque e em trânsito, aumentando a agilidade da cadeia de suprimentos. 


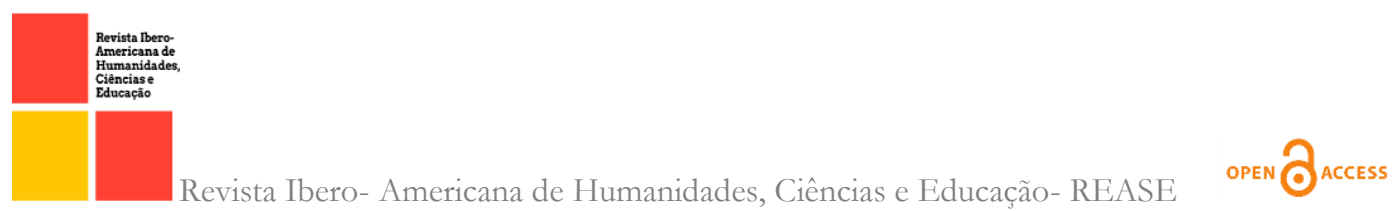

Manter parceiro alinhados com a estratégia da empresa, é a melhor opção para o sucesso, estabelecendo incentivos para aqueles que colaboram, como fornecedores qualificados, as entregas podem ser dispensadas de verificações individuais, poupando tempo daquele que faz a entrega, agilizando o processo e economizando dinheiro.

\section{CONCLUSÃO}

O objetivo deste trabalho é contribuir para análise e compreensão que a gestão na cadeia de suprimentos proporciona competitividade de maneira contínua entre as empresas, o Supply Chain, está inserido em contextos cada vez mais desafiador mais complexo, e a forma de lidar com estes desafios é simplificar, eliminando os desperdícios com processos mais enxutos, é investindo em tecnologia.

O futuro do Supply Chain Management depende da Simplificação, no desenvolvimento de Tecnologia e das relações de Colaboração, e poderá ser aprofundado em estudos futuros, neste contexto conclui-se, que com a gestão da cadeia de suprimentos é possível aumentar a competitividade entre as empresas, com atividades desenvolvidas através de ferramenta que contribuam para o planejamento na distribuição de produtos, e aquisição de matéria prima, e armazenamento, com redução dos custos e aumentando a competitividade diante do mercado que é extremamente competitivo, desenvolvendo mecanismos propício para identificar, e disseminar o conhecimento agregando valor à organização, com metas e objetivos, atingindo o consumidor final com celeridade, com produtos de qualidade.

\section{REFERÊNCIAS BIBLIOGRÁFICAS}

Christopher, M. (2012). Logística e Gerenciamento da Cadeia de Suprimentos. (C. Learning, Ed.) São Paulo, São Paulo, Brasil: Cengage Learning.

Cristopher, M. (2007). Logística e Gerenciamento da Cadeia de Suprimentos. Criando redes que agregam valor. (2a). (C. Learning., Ed.) São Paulo:, São Paulo:, Brasil: Cengage Learning. 
MIGUEL, P. L., \& BRITO, L. A. (23 de Setembro de 2009). A Gestão da Cadeia de Suprimentos e sua Conexão com a Visão Relacional da. (X. EnANPAD, Ed.) São Paulo, São Paulo, Brasil: XXXIII EnANPAD. Acesso em 2i de 04 de 202I, disponível em http://www.anpad.org.br/diversos/down_zips/45/GOLi965.pdf

NOVAES, A. G. (2004). Logística e Gerenciamento da Cadeia de Distribuição. (2a. Edição Revista e Atualizada,). (Campus, Ed.) Rio de Janeiro, Rio de Janeiro, Brasil: Campus. Acesso em 202I de abril de 2I, disponível em https://www.revistaespacios.com/ar3v34no4/13340405.html

NOVAES, A. G. (2015). Logística e gerenciamento da cadeia de distribuição. (Elsevier, Ed.) Rio de Janeiro, Rio de Janeiro, Brasil: Elsevier. Acesso em 20 de abril de 202I, disponível em https://periodicos.uem.br/ojs/index.php/rev_prod 